\title{
APLICAÇÃO DO ÍNDICE DE SINUOSIDADE DE FRENTE DE ESCARPA PARA IDENTIFICAÇÃO DE SETORES SOB INFLUÊNCIA TECTÔNICA EM RECORTE DA BORBOREMA NA BACIA DO RIO PARAÍBA DO MEIO - AL
}

\author{
João Paulo da Hora Nascimento ${ }^{(a)}$, Paulo de Tarso Barbosa Leite ${ }^{(b)}$, Priscila Emanoelle Claudino \\ Silva $^{(c)}$, Kleython de Araujo Monteiro ${ }^{(d)}$ \\ (a) Instituto de Geografia, Desenvolvimento e Meio Ambiente, UFAL, geografojoao@outlook.com \\ (b) Instituto de Geografia, Desenvolvimento e Meio Ambiente, UFAL, tarso.geoufal@gmail.com \\ (c) Instituto de Geografia, Desenvolvimento e Meio Ambiente, UFAL, emanoelle.priscilla@ gmail.com \\ (d) Instituto de Geografia, Desenvolvimento e Meio Ambiente, UFAL, geokleython@ gmail.com
}

\section{EIXO: SISTEMAS GEOMORFOLÓGICOS: ESTRUTURA, DINÂMICAS E PROCESSOS}

\begin{abstract}
Resumo
Este trabalho conta com a aplicação de parâmetros morfométricos como ferramentas importantes para a anállise geomorfológica da paisagem. O índice de Hack (IH), e posteriormente o indice de Sinuosidade de Frente de Escarpa foram aplicados a área do rio Paraíba do Meio com intuito de verificar a atuação de tetônica recente como controladora importante da estruturação do relevo. Foi vefiricado que em menor escala temos valores de médios para altos, pois os setores são mais generalizados. Quando aumentamos a escala encontramos o detalhe e os valores ficam mais próximo de 1, evidenciando maior influência dos esforços tectônicos.
\end{abstract}

Palavras chave: Tectônica. Sinuosidade de Frente de Escarpa. Planalto da Borborema.

\section{INTRODUÇÃO}

Os estudos geomorfológicos têm contado, desde 1970 com uma série de parâmetros que auxiliam no estudo da paisagem, abrindo possibilidade de esclarecer o funcionamento de grandes unidades do modelado, sendo estas compreendidas como produtos de diversos processos atuantes em variadas escalas temporais. Estas técnicas, entre elas as morfométricas, têm contribuído enormemente para a análise objetiva das formas do modelado por serem de fácil aplicação, de baixo custo e apresentarem resultados reais, passíveis de comparação, além da adaptação a diferentes contextos climáticos e estruturais. O presente trabalho busca aplicar o índice de Sinuosidade de Frente de Escarpa (Smf - Sinousity Mountain Front) na área da bacia do rio Paraíba do Meio.

As escarpas apresentam-se como importantes formas, talvez as principais estruturas, para os estudos evolutivos do relevo, já que estas são produtos da intensa relação entre forças endógenas e processos erosivos de superfície. São indicativas do grau de evolução da paisagem, além de evidenciar os processos atuantes mais intensos na produção das formas. Ver Penck (1924). O Índice de Sinuosidade de Frente de 
Escarpa proposto por Bull e McFadden (1997) relaciona a morfologia com os processos erosivos e/ou soerguimentos ao longo da frente de uma escarpa, apresentando valores que podem ser comparados com outros setores ao longo da Escarpa Oriental da Borborema.

\section{CARACTERIZAÇÃo DA ÁREA}

\subsection{Rio Paraíba do Meio}

O rio Paraíba do Meio está localizado na macrorregião do Nordeste brasileiro e abrange uma área de 3.330 $\mathrm{km}^{2}$, tendo sua nascente no estado de Pernambuco, no extremo oriental da Serra do Grande. Possui direção geral sudeste ao longo dos seus 172 km de extensão, e deságua no Complexo Estuário Lagunar MundaúManguaba no litoral de Alagoas.

A Borborema por se tratar de relevo estruturado em plataforma antiga apresenta longo período evolutivo onde houve, dentre outras mudanças significativas, o rebaixamento das cadeias montanhosas devido a atuação da denudação e na sequência exposição de rochas graníticas mais recentes. Admite-se para a região a influência de arqueamento. Em compartimentação estrutural proposta por Corrêa et al. (2010) o rio Paraíba do Meio está localizado na Cimeira Estrutural Pernambuco-Alagoas. Caracterizada por apresentar feições topográficas homogêneas (Complexo Gnáissico-Migmatítico), marcadas por cimeiras planas, cuja elevação varia entre 600 e 700 metros.

\subsection{Metodologia}

Para aplicar o índice de Sinuosidade de Frente de Escarpa precedeu-se a definição de linha de escarpa, sendo esta definida pelo maior valor de anomalia de drenagem encontrada por Nascimento et al. (no prelo). O índice Smf proposto por Bull e McFadden (1997) busca relacionar o balanço de energia entre as forças erosivas e tectônicas atuantes em uma escarpa, dessa maneira, é utilizado para evidenciar a atuação de processos tectônicos ao longo de uma encosta ou escarpa.

O índice de Smf é calculado a partir da fórmula:

$$
\mathrm{Smf}=\mathrm{Lmf} / \mathrm{Ls}
$$

onde Smf significa índice de Sinuosidade da Frente de Escarpa; Lmf, comprimento da linha atual da frente de escarpa; Ls, comprimento da linha reta. Os valores próximos a 1 demonstram a influência de tectônica, 


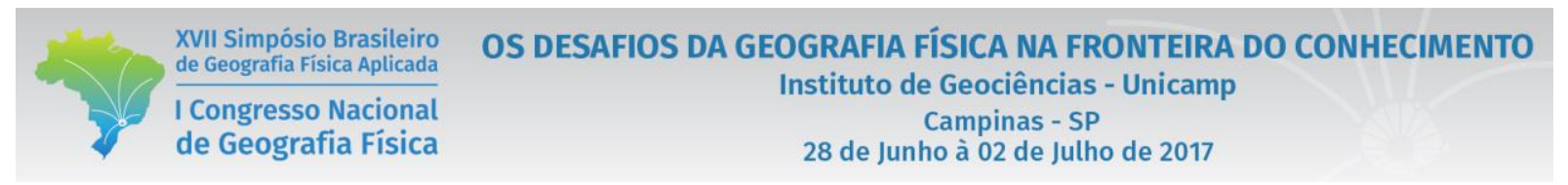

os valores maiores que 3 evidenciam maior atuação de processos erosivos na estruturação do relevo, excluindo, ou reduzindo significativamente a possibilidade de atuação ou controle tectônico; já aqueles próximos a 2 indicam um estado intermediário.

Para identificação do índice de sinuosidade a linha de escarpa foi dividida em 2 níveis, adotando escalas diferentes, onde os trechos iniciais (menor escala) deram lugar a subdivisões (maior escala), assim, foi possível identificar com precisão mais detalhada a tendência evolutiva da escarpa estabelecida.

\section{RESULTADOS E DISCUSSÃO}

A partir da identificação das anomalias de drenagem, entendidas como rupturas de patamar da bacia rio Paraíba do Meio, onde foi registrado o maior valor do índice de Hack - isoípsa 175m (NASCIMENTO et al. no prelo), foi estabelecido a transição encosta - base. Posteriormente foi aplicado o índice Smf ao longo de setores da linha de escarpa, seguindo duas escalas distintas (Figura 1).

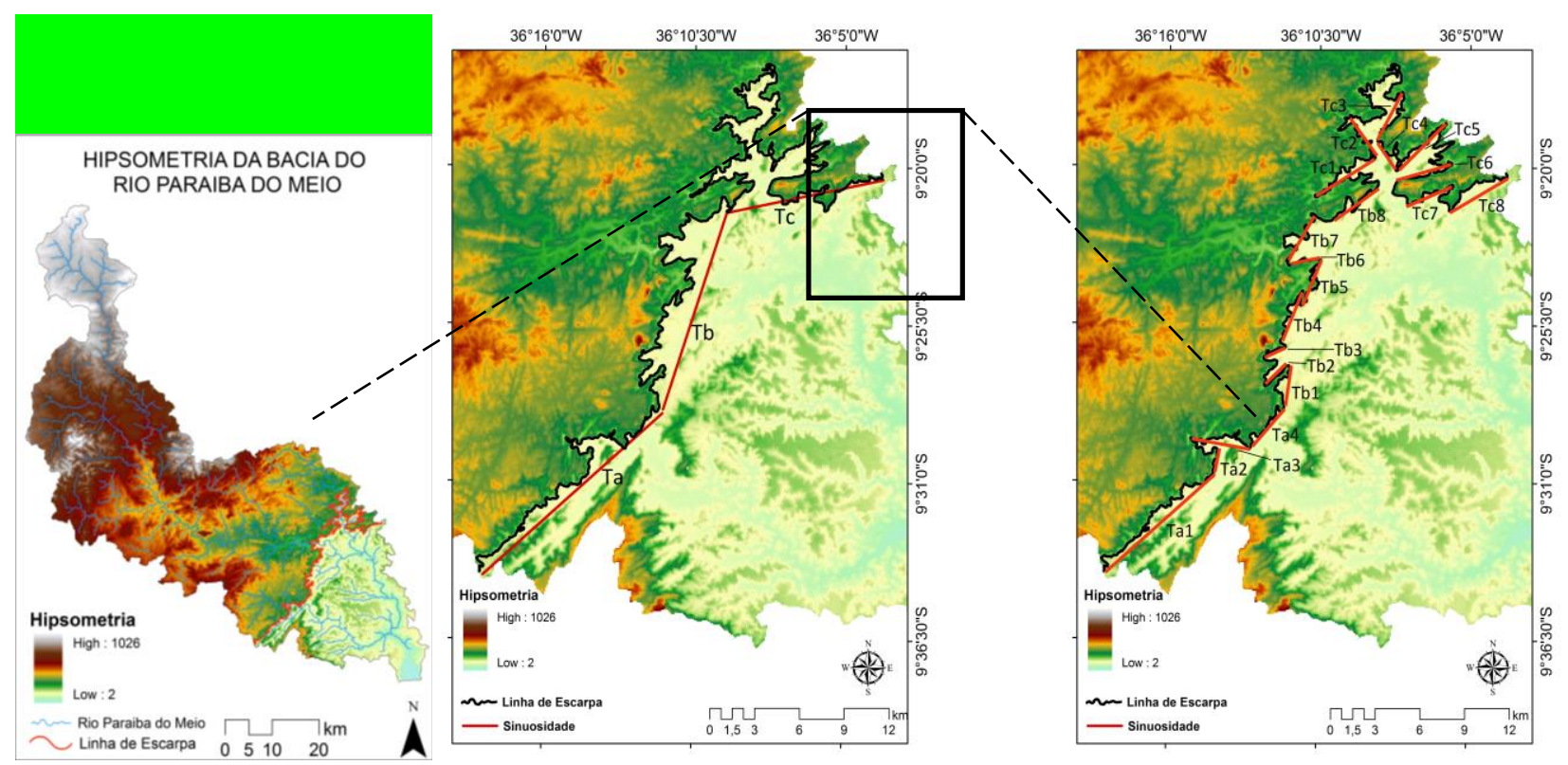

Figura 1: Mapa de localização do Rio Paraíba do Meio e Recortes 1 e 2. 
Os valores do índice Smf podem ser verificados nas Tabelas 1 e 2.

Tabela I: índice de sinuosidadae por recorte- 1

\begin{tabular}{c|c|c|c}
\hline Recorte 1 & Escarpa & Linha Reta & Sinuosidade \\
\hline $\mathrm{Ta}$ & 30,793 & 15,893 & 1,937 \\
\hline $\mathrm{Tb}$ & 38,953 & 13,441 & 2,898 \\
\hline $\mathrm{Tc}$ & 87,156 & 10,659 & 8,176
\end{tabular}

Tabela II: Índice de sinuosidade por recorte- 2

\begin{tabular}{c|c|c|c}
\hline Recorte 2 & Escarpa & Linha Reta & Sinuosidade \\
\hline Ta1 & 14,227 & 9,633 & 1,476 \\
\hline Ta2 & 1,783 & 1,565 & 1,139 \\
\hline Ta3 & 6,492 & 3,997 & 1,624 \\
\hline Ta4 & 5,337 & 3,226 & 1,654 \\
\hline Tb1 & 4,039 & 2,634 & 1,533 \\
\hline Tb2 & 2,244 & 1,929 & 1,163 \\
\hline Tb3 & 2,222 & 1,526 & 1,456 \\
\hline Tb4 & 5,276 & 3,417 & 1,544 \\
\hline Tb5 & 5,513 & 3,227 & 1,708 \\
\hline Tb6 & 2,484 & 1,989 & 1,248 \\
\hline $\mathrm{Tb} 7$ & 8,033 & 3,322 & 2,418 \\
\hline $\mathrm{Tb} 8 *$ & 6,368 & 3,643 & 1,748 \\
\hline $\mathrm{Tc} 1$ & 6,889 & 4,588 & 1,501 \\
\hline $\mathrm{Tc} 2$ & 7,187 & 3,033 & 2,369 \\
\hline $\mathrm{Tc} 3$ & 5,094 & 3,48 & 1,463 \\
\hline $\mathrm{Tc} 4$ & 4,919 & 2,087 & 2,356 \\
\hline $\mathrm{Tc5}$ & 5,348 & 4,315 & 1,239 \\
\hline $\mathrm{Tc} 6$ & 4,532 & 3,834 & 1,182 \\
\hline $\mathrm{Tc} 7$ & 4,182 & 3,317 & 1,260 \\
\hline $\mathrm{Tc} 8$ & 6,153 & 4,457 & 1,380
\end{tabular}

Obs. o traço de linha reta correspondente os trecho $\mathrm{Tb} 8$ está dividido entre os setores $\mathrm{Tb}$ e $\mathrm{Tc}^{*}$

No recorte de menor escala, onde a escarpa foi dividida em três setores, 2 dos valores encontrados demonstram não haver para os trechos T2 e T3 influencia tectônica recente na estruturação do relevo, sobressaindo-se os processos denudacionais. Obtendo respectivamente os índices 2,898 e 8,176. Já o trecho 1, com índice de 1,937, pode ser considerado como resultante do equilíbrio entre estes processos, sugerindo atuação tectônica moderada.

$\mathrm{Na}$ divisão estruturada em maior escala, cada setor já traçado ganhou novas divisões. Estas subdivisões, por sua vez, permitiram a identificação da atuação local de processos morfoestruturais. Como foi possível 
identificar, nenhuma das subdivisões apresentam valores maiores que 3. Apenas 3 dos trechos tiveram cifras superiores a 2: Tb7 (2,418); Tc2 $(2,369)$ e Tc4 (2,356). Os demais valores se aproximaram de 1.

Assim, os valores encontrados apontam para a atuação e influência de tectônica para o setor da Borborema na bacia do rio Paraíba do Meio.

\section{CONSIDERAÇÕES FINAIS}

Aplicado posteriormente ao índice de Hack, o índice de Sinuosidade de Frente de Escarpa se mostra de grande importância, na medida em que pode contribuir para identificar atuação de processos tectônicos recentes como condicionantes do relevo regional.

A adoção de escalas variadas pode contribuir para identificação de determinados processos, a exemplo: os tectônicos. Onde ao se estabelecer maior escala, há uma maior aproximação do traçado com os lineamentos de relevo.

\section{REFERÊNCIAS}

BULL, W.; MCFADDEN, L. Tectonic geomorphology north and south of the Garlock fault, California. In: Proceedings Vol. of 8th Annual Geomorph. Symp. (Edited by Doering, D.O.) State University of New York at Binghamton, Binghamton, NY. 1977, 116-138. 1977.

CHRISTOFOLETTI, A. Geomorfologia. São Paulo: Editora da Universidade de São Paulo, 1974. p. 149.

CORREA, A. C. B. et al. Aplicação do índice de Hack no rio Ipojuca para identificação de setores anômalos de drenagem e rupturas de relevo. Geociências, São Paulo, v. 33, n. 4, p. 616-628, 2014.

HACK, J. T. Stream-profile analysis and streamgradient index. Journal of Research of the U0.S. Geological Survey v. 1, n. 4: 421-429. 1973.

NASCIMENTO, J. P. H. et al. Identificação de anomalias de drenagem no rio Paraiba Do Meio (PE/AL) a rartir da aplicação do Índice e Hack. Revista CLIO - Arqueológica. No prelo.

PENCK, W. Die morphologische analyse. Ein kapitel der physikalischen geologie. J. Engelhorn's Nachf. Stuttgart, 283p. 1924. 